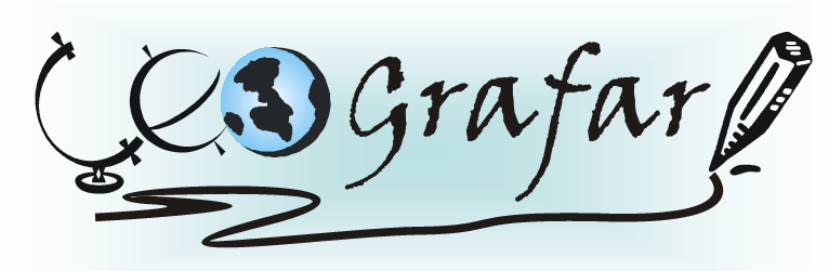

Revista Eletrônica do Programa de Pós-Graduação em Geografia - UFPR

\title{
ANÁLISE TEMPORAL DE IMAGENS ORBITAIS COM DIFERENTES MAGNITUDES DE CHEIAS E VARIÁVEIS HIDROLÓGICAS DO RIO IVAÍ EM SEU CURSO INFERIOR, PR
}

\section{TEMPORAL ANALYSIS OF ORBITAL IMAGES WITH DIFFERENT MAGNITUDES OF FLOODS AND HYDROLOGIC VARIABLES ON THE LOWER COURSE OF IVAÍ RIVER, PR}

(Recebido em 22.05.2012; Aceito em 09.02.2013)

\author{
Fabio Corrêa Alves \\ Graduando em Geografia - UEM \\ Maringá, PR, Brasil \\ e-mail: alves.fabioc@gmail.com \\ Manoel Luiz dos Santos \\ Profo Dro do Departamento de Geografia - UEM \\ Maringá, PR, Brasil \\ e-mail:mluisdossantos@gmail.com
}

\begin{abstract}
Resumo
Eventos de cheias, com consequente propagação de inundação através do canal fluvial e sua planície podem causar prejuízos sociais e econômicos como a perda de produtividade agrícola e danos as instalações agropecuárias. A variação no regime de vazões interfere em importantes transformações na morfologia de leito do canal, no transporte de sedimentos, bem como na cobertura vegetal e conectividade com o ecossistema aquático da planície aluvial. A bacia hidrográfica do rio Ivaí é a segunda maior do Estado do Paraná, com grande importância econômica, social e ambiental para a região. O rio Ivaí é um importante tributário da margem esquerda do rio Paraná que até o momento não possui barramentos, revelando-se como importante objeto de estudo dos seus aspectos hidrodinâmicos. Apesar disso, pouco foi abordado em relação a dinâmica de suas cheias. Sendo assim, o presente trabalho tem como objetivo analisar as cheias ocorrentes no curso inferior deste sistema
\end{abstract}


fluvial. Para tanto, selecionaram-se imagens orbitais dos satélites Landsat 4 e 5 sensor MSS que contemplaram períodos de cheia. Além disso, na tentativa de definir os níveis de inundação na planície aluvial, foram analisadas as variáveis hidrológicas do rio Ivaí. A utilização de imagens orbitais para análise temporal de eventos de cheias do rio Ivaí possibilitaram de forma indireta a verificação de transformações ocorrentes em sua planície aluvial. A relação com variáveis hidrológicas proporcionou a caracterização preliminar da dinâmica de inundação deste importante sistema fluvial paranaense, embora tenha sido utilizado um conjunto restrito de variáveis e imagens orbitais. Verificou-se a importância da cheia de 17/01/1990, que com valores de vazão próximos a média das cheias registradas na estação fluviométrica de Novo Porto Taquara, promoveu a inundação da área em patamares mais elevados da planície aluvial, sendo também verificada na planície aluvial do alto rio Paraná e rio Ivinhema. Os valores de precipitação pluviométrica nos cursos médio e superior da bacia hidrográfica contribuíram para a elevação do nível das águas do rio e concomitantemente alimentam as cheias deste sistema fluvial.

Palavras-Chave: Sistema fluvial, planície aluvial, geomorfologia fluvial, sensoriamento remoto.

\section{Abstract}

Flood events, with consequent propagation of flooding through the river channel and its flood plain can cause economic loss over the agricultural productivity and damages to agricultural and social installations. The variation in flow regime can cause important transformations on the morphology of the channel bed and sediments transport, also on vegetation and aquatic ecosystem connectivity on alluvial plain. The Ivaí River basin is the second largest of the State of Paraná, with economic and environmental importance to the region. The Ivaí River is a tributary of the left bank of the Paraná River, with no dams in its course, revealing itself as an important object of study of its hydrodynamic aspects. Despite this, there are few studies on the flooding dynamics. In this study were selected satellite images showing floods of MSS sensor in the 4 and 5 Landsat satellites. These images were analyzed together hydrologic variables of Ivaí River. The use of satellite images for temporal analysis of flood events of Ivaí River enabled the verification of transformations occurring in its alluvial flood plain. The relation with hydrological variables provided a preliminary characterization of flooding dynamic on the Paraná fluvial system, even if used a restricted set of variables and few satellite images. Cheking the importance of a flood event in 01/17/1990 on the Ivaí River, that even with values of flow near the average flood, measures at the fluviometric station Novo Porto Taquara, promoted flooding in higher levels of the alluvial plain, was also verified in the alluvial plain of the upper Paraná River and Ivinhema River. The values of rainfall precipitation in the middle and upper course of watershed contributed to raising the level of the Ivaí River and concomitantly feeding the floods.

Keywords: Fluvial system, alluvial plain, fluvial geomorphology, remote sensing. 


\section{Introdução}

No que tange a investigação do regime hidrológico em importantes sistemas fluviais tropicais no Brasil, poucos foram os estudos, apesar do elevado potencial hídrico apresentado por este país (CLARKE et al., 2003; DESTEFANI, 2005; AQUINO et al., 2008; SOUZA FILHO, 2009).

Eventos de cheias, com consequente propagação de inundação através do canal fluvial e sua planície podem causar instabilidade para o ambiente, economia e sociedade. As variações no regime de vazões interferem em importantes transformações na morfologia de leito do canal e no transporte de sedimentos, bem como na cobertura vegetal e conectividade com o ecossistema aquático da planície aluvial, como constatado por Comunello (2001); Rocha (2002); Comunello et al., (2003); Couto et al., (2010).

Nem toda cheia causa inundações, sendo que a enchente é caracterizada por uma vazão grande de escoamento e as inundações são consideradas quando ocorre extravasamento das águas do canal para a planície (VILLELA e MATTOS, 1975). Além disso, podem ser encontradas dificuldades na escolha de indicadores morfológicos para a atribuição do nível de margens plenas que delimitam os processos do canal com os processos geomorfológicos da planície de inundação (FERNANDEZ, 2003).

A bacia hidrográfica do rio Ivaí apresenta grande importância econômica, social e ambiental para o estado do Paraná. Além disso, este rio não possui barramentos, revelando-se como importante objeto de estudo nos seus aspectos hidrodinâmicos, embora exista, uma forte intenção do poder público para o aproveitamento do potencial hidroelétrico deste sistema fluvial. Os aspectos hidrosedimentológicos foram estudados no seu curso inferior por Biazin (2005); Barros (2006); Kuerten (2006); Kuerten et al., (2009); Santos et al., (2010), geomorfológico por Santos et al., (2008) e Morais (2010) que estudou a gênese e evolução da planície de inundação na região de sua confluência fluvial.

O regime hidrológico do rio Ivaí foi estudado por Destefani (2005) que constatou na região de seu curso inferior, para a estação fluviométrica de Novo Porto Taquara entre o período de 1974-2002, uma vazão média anual de $728 \mathrm{~m} 3 / \mathrm{s}$ e 
a média das cheias com $4019 \mathrm{~m}^{3} / \mathrm{s}$. Segundo a mesma autora, esse rio não apresenta uma nítida caracterização de períodos de cheia e de vazante, podendo esses regimes ocorrer em qualquer época do ano, consequência de fatores como, o clima, formato da bacia, declividade e litologia. Embora Santos et al., (2010) tenha realizado um estudo recente destacando o comportamento das cheias do rio Ivaí no seu curso inferior, a análise temporal por meio de imagens orbitais que contemplem diferentes magnitudes de cheias e relação com a dinâmica de inundação ainda não foram realizadas.

A utilização do Sensoriamento Remoto por imagens orbitais na identificação de grandes áreas inundáveis surge por meio de sensores passivos, como o MultiSpectral Scanner (MSS), conforme utilizado por Smith (1997). Por não existir um monitoramento contínuo de variáveis hidrológicas na região de confluência fluvial do rio Ivaí com o canal secundário do rio Paraná, não é possível definir um nível de inundação nesta área, pelo não conhecimento da influência de ambos os sistemas fluviais. Sendo assim, a busca de dados por meio de imagens orbitais, pode tornarse uma importante fonte alternativa. Além disso, o monitoramento de forma indireta da superfície terrestre permite a caracterização de áreas até então de difícil acesso em campo.

Desta forma, torna-se oportuna a investigação das cheias deste importante sistema fluvial, proporcionando assim, a identificação de diferentes situações de inundação em sua planície aluvial.

\section{Área de estudo}

A bacia hidrográfica do rio Ivaí é a segunda maior do estado do Paraná e abrange uma área de drenagem com aproximadamente $36.540,02 \mathrm{~km}^{2}$, localizandose entre as coordenadas $22^{\circ} 56^{\prime} 17^{\prime \prime}-25^{\circ} 35^{\prime} 27^{\prime \prime}$ de latitude sul e $50^{\circ} 44^{\prime} 17^{\prime \prime}-53^{\circ} 41^{\prime} 43^{\prime \prime}$ de longitude oeste, região sul do Brasil, Figura 1. O rio Ivaí é um importante tributário da margem esquerda do rio Paraná, nasce na confluência dos rios dos Patos e São João na região do Segundo Planalto do Paraná e percorre 
aproximadamente $671 \mathrm{~km}$ de curso até desaguar nas águas do rio Paraná no Terceiro Planalto Paranaense.

O clima na bacia hidrográfica apresenta dois tipos diferentes, sendo tropical ao norte e subtropical ao sul. No baixo curso do rio Ivaí a precipitação média é de $1300 \mathrm{~mm}$ e as temperaturas oscilam entre $22^{\circ} \mathrm{C}$ no verão e $18^{\circ} \mathrm{C}$ (ou menos) durante o inverno (PARANÁ, 1987).
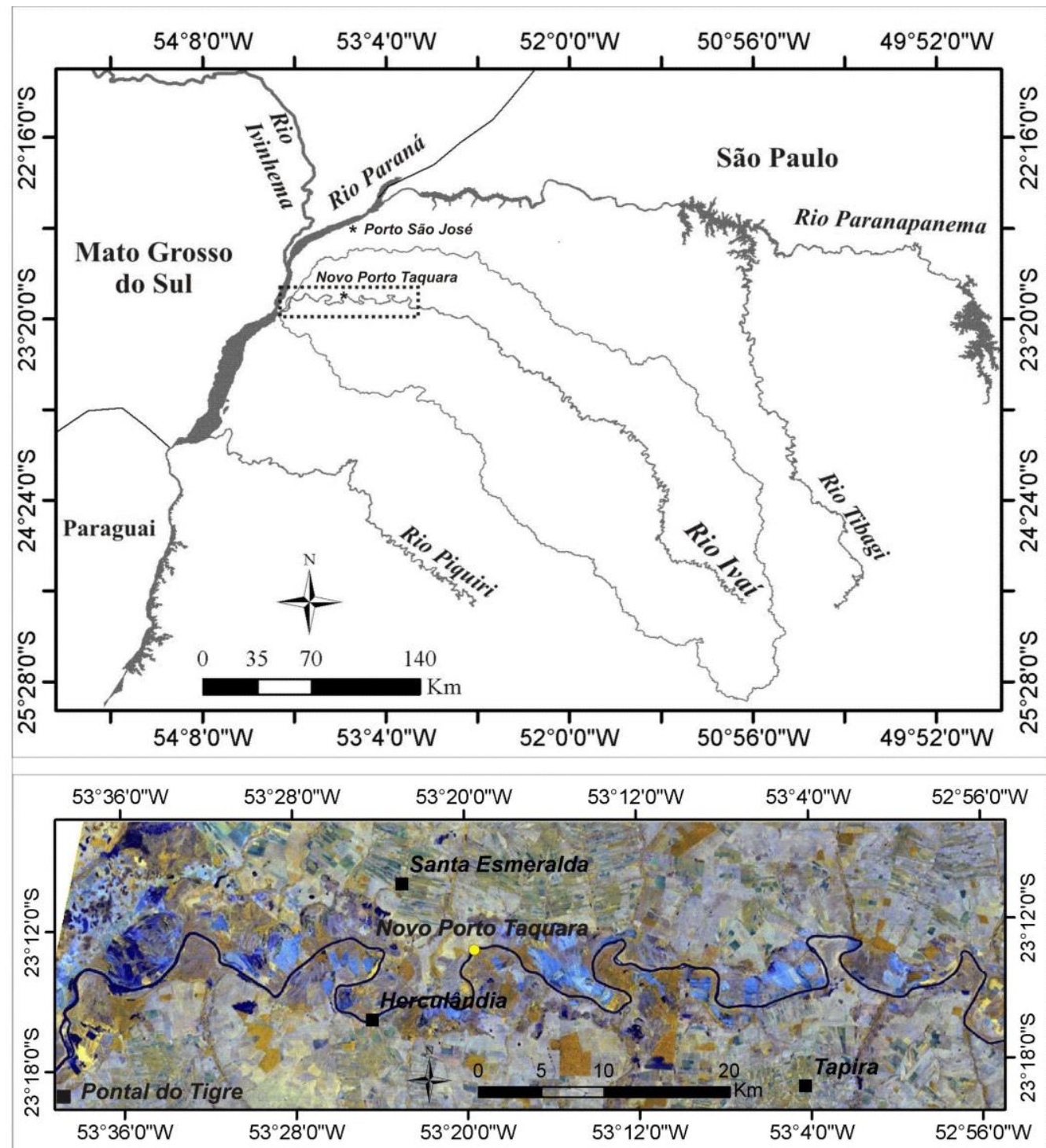

Figura 1 - Localização da bacia hidrográfica do rio Ivaí e a planície aluvial em seu curso inferior. Observa-se ao fundo da imagem o realce do canal fluvial na cor azul escuro, data em que foi registrado um dos menores valores de nível fluviométrico e vazão na série histórica ( $90 \mathrm{~cm}$ e $177 \mathrm{~m}^{3} / \mathrm{s}$, respectivamente) por meio da estação fluviométrica de Novo Porto Taquara.

Fonte: Base: Imagem Landsat 4 sensor MSS de 05/12/1985 na composição colorida falsa cor R4G3B1 
O rio Ivaí na região noroeste de sua bacia hidrográfica se desenvolve sob as camadas Mesozóicas da bacia sedimentar do Paraná, representadas pela Formação do arenito Caiuá (Grupo Bauru) e por sedimentos recentes aluvionares (SOARES et al.,1980; MINEROPAR, 2000). Nos últimos 150km de canal deste rio, ele desenvolve sua planície aluvial, formada por terraços aluviais do antigo sistema do rio Ivaí que estão cerca de 5 a $8 \mathrm{~m}$ acima da atual planície de inundação do rio (SANTOS et al., 2008). Além disso, o canal fluvial apresenta-se com alta sinuosidade (Figura 1), recebendo forte controle litológico e tectônico, constatado recentemente por Souza Junior (2012). A planície aluvial registra inúmeros paleocanais e paleomeandros do antigo sistema meandrante deste rio.

\section{Materiais e métodos}

Para análise temporal de diferentes magnitudes de cheias do rio Ivaí em seu curso inferior, procurou-se imagens orbitais que contemplassem a cena e que apresentassem em menor condição de nuvens possível. No entanto, devido a sua pouca existência, foram selecionadas apenas quatro imagens orbitais de cheia referentes aos satélites Landsat 4 e 5 sensor Multispectral Scanner System (MSS) na órbita/ponto 223/076.

Segundo Jensen (2009), essas imagens limitam-se a resolução espacial de $79 \times 79$ metros e espectral com 4 bandas $1,2,3$ e 4 , correspondendo aos comprimentos de onda do verde, vermelho e infravermelho próximo refletido. Contudo, as imagens orbitais dos satélites Landsat 4 e 5 sensor MSS disponíveis por intermédio do site: http://glovis.usgs.gov/, encontram-se georreferenciadas e com resolução espacial de $60 \times 60$ metros. As imagens selecionadas correspondem às datas de 05/12/1982, 15/06/1983, 21/10/1983 e 17/01/1990. Posterior a escolha das imagens, realizaram-se composições coloridas por meio do software ENVI 4.5 (RSI, 2008), permitindo assim, o realce das áreas úmidas e os diferentes alvos presentes na imagem.

Com a finalidade de se apresentar a topografia e declividade da área estudada foi utilizada imagem da missão Shuttle Radar Topography Mission, 
(SRTM), disponível gratuitamente no banco de dados do Instituto Nacional de Pesquisas Espaciais (INPE) por intermédio do site: http://www.dsr.inpe.br/topodata. Essas imagens foram interpoladas para a resolução espacial de 30 metros, conforme procedimentos metodológicos apresentados por Valeriano e Rossetti (2011). Posterior à seleção da imagem, recortou-se a área de interesse e foram definidos intervalos de valores, atribuindo cores as classes temáticas, visando uma melhor representação cartográfica por meio do software ArcGIS 9.3 (ESRI, 2006).

$\mathrm{Na}$ caracterização dos diferentes níveis de água na planície aluvial, foram utilizados valores diários da série histórica de nível fluviométrico, vazão e precipitação pluviométrica (anterior e posterior à data da imagem), por meio do banco de dados da estação fluviométrica de Novo Porto Taquara (código 64693000), localizada cerca de $50 \mathrm{~km}$ a montante da foz do rio Ivaí. Os valores de precipitação diária $(\mathrm{mm})$ foram obtidos na estação pluviométrica de Novo Porto Taquara (código 2353044) distando cerca de $12 \mathrm{~km}$ da primeira. Além disso, na tentativa de verificar a influência do rio Paraná nas cheias ocorrentes no curso inferior do rio Ivaí, foram analisados os valores de cota fluviométrica disponíveis por meio da estação de Porto São José (código 64575003) no Rio Paraná, ao norte da área estudada. No entanto, além da ausência no registro de dados no período de 1983, foi observado em relação ao período analisado neste trabalho que, o rio Paraná estava em cheia apenas no ano de 1990.

As variáveis hidrológicas são disponibilizadas gratuitamente pela Agência Nacional de Águas (ANA) no site: http://www.ana.gov.br/portalsnirh/. Para todos os casos, utilizou-se do software Microsoft Office Excel 2010 no tratamento estatístico das variáveis.

\section{Resultados e discussões}

A região de foz do rio Ivaí (Pontal do Tigre) reflete os primeiros estágios de inundação, por estar localizada em uma área com altitudes menores que $268 \mathrm{~m}$ e declividades inferiores a $2 \%$ respectivamente, Figura 2 . Segundo Santos et 
al.,(2008) nesta região, o rio Ivaí não apresenta diques marginais em sua margem direita, favorecendo assim, a dinâmica da inundação.

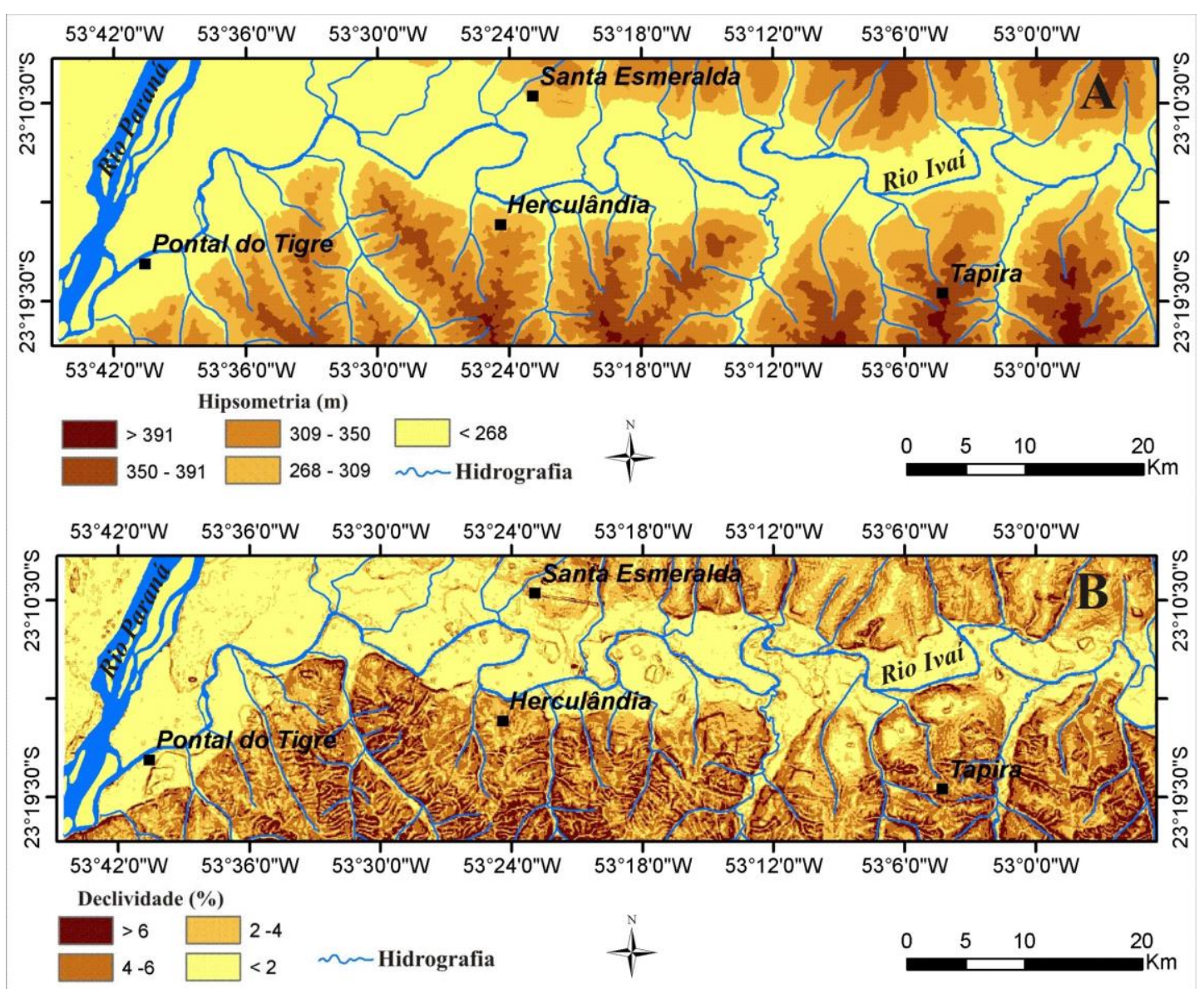

Figura 2 - (A) Altimetria da região de planície aluvial do rio Ivaí; (B) classes de declividade. Fonte: Base: Dados da missão SRTM

A interdependência dos sistemas fluviais na região de confluência fazem com que aconteça o barramento das águas do rio Ivaí pelo canal secundário do rio Paraná, ou a situação oposta, promovendo a inundação da área e decantação de partículas, fato esse, observado por Biazin (2005).

As imagens orbitais com diferentes magnitudes de cheias são ilustradas na Figura 3. Observam-se em todas elas, o realce da água (classificada com a cor azul na imagem) em diferentes situações no canal fluvial e na planície aluvial do rio Ivaí.

Em 05/12/1982, na estação fluviométrica de Novo Porto Taquara, registraramse os valores de 6,45 m de cota fluviométrica diária e 1663,5 m³/s de vazão. Nesta data, não foram verificadas expressivas transformações pela água na planície, embora tenha se observado por meio das feições geomorfológicas e seu 
posicionamento a jusante da estação fluviométrica que, a água reestabeleceu conexão nas partes baixas em paleocanais e ambientes lênticos, identificadas na imagem pelo realce nas tonalidades de cores preta e azul.

Na respectiva estação, foram registrados em 21/10/1983 os valores de 6,19 m de cota fluviométrica e $1577,7 \mathrm{~m}^{3} / \mathrm{s}$ de vazão, sendo, portanto, valores inferiores quando comparados por aqueles registrados em 1982. No entanto, foi observado na imagem de 1983 que a planície aluvial revela com maior realce as feições de áreas úmidas, embora se apresente em baixa qualidade visual, Figura 3. A provável justificativa para este fato, esta em relação a resposta do sistema fluvial na planície, devido a condição hidrológica imposta nos dias que antecederam a data do imageamento pelo satélite, Figura 4.
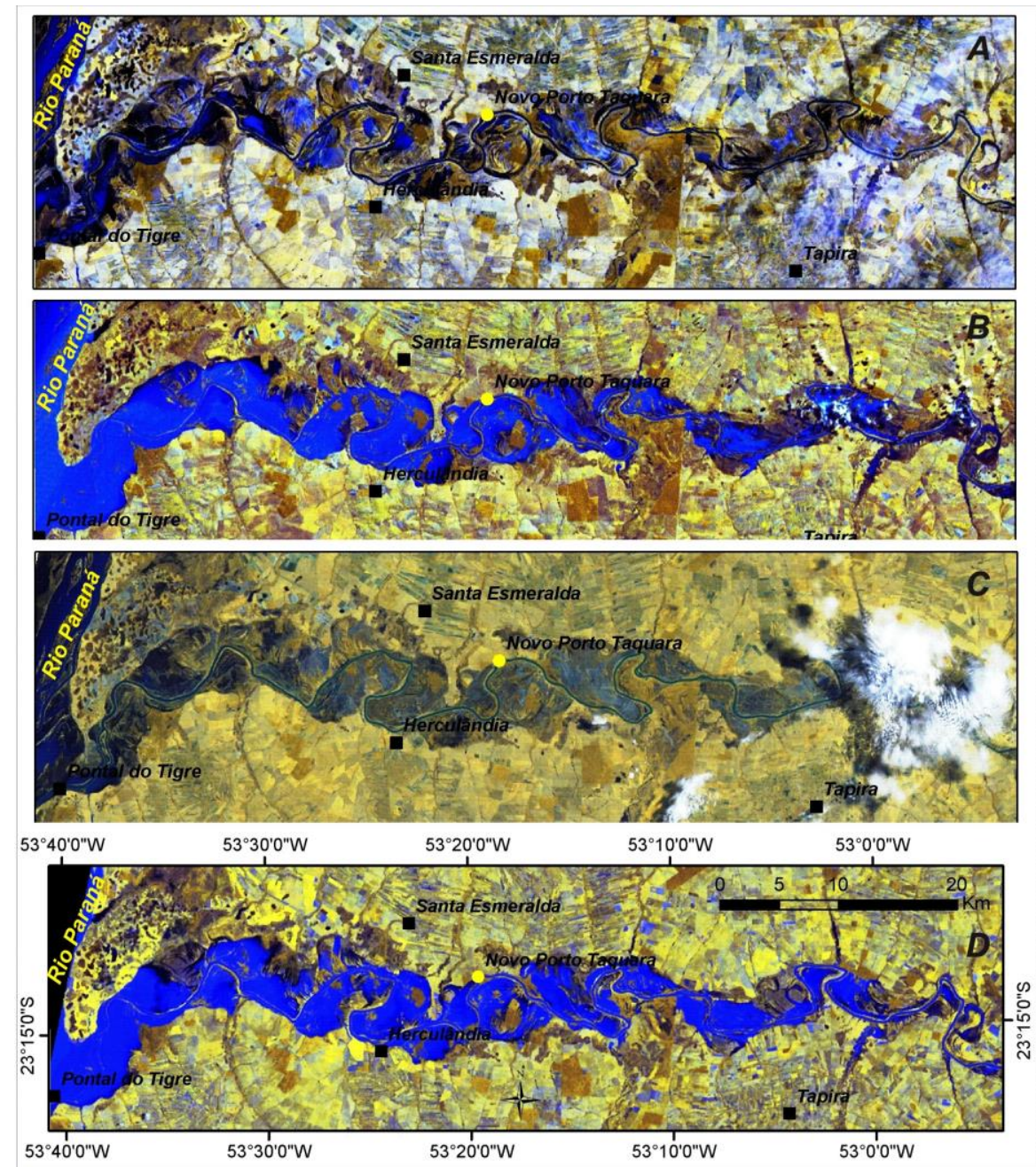

Figura 3 - Eventos de cheias ocorrentes na planície aluvial do rio Ivaí; (A) 05/12/1982, (B) 15/06/1983, (C) 21/10/1983 e (D) 17/01/1990.

Fonte: Imagens orbitais Landsat 4 e 5 sensor MSS na composição colorida falsa cor R4G3B1 


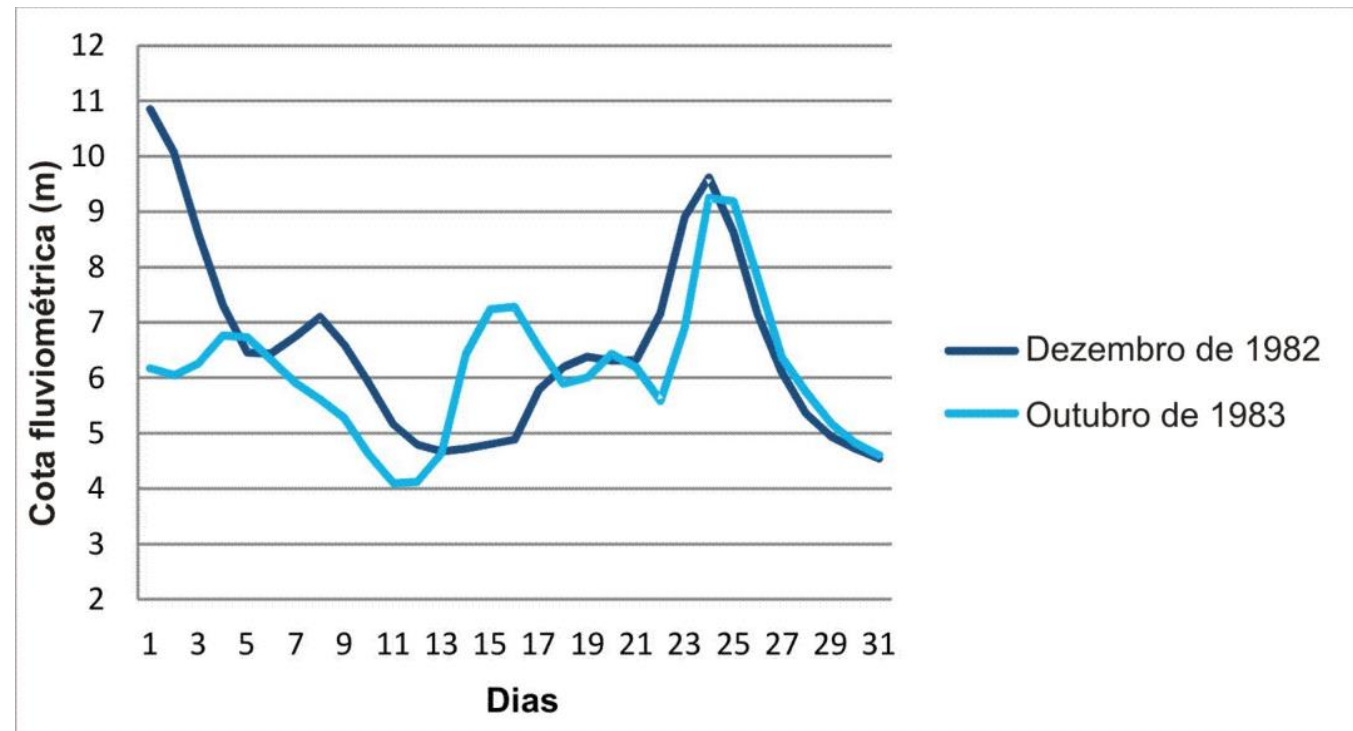

Figura 4 - Valores diários de cota fluviométrica $(\mathrm{m})$ do rio Ivaí nos meses que ocorreram as cheias de 05/12/1982 e 21/10/1983 respectivamente, por meio da estação fluviométrica de Novo Porto Taquara (código 64693000)

Verifica-se na Figura 4 que a distribuição dos valores de cota fluviométrica nos dias que antecedem a cheia de 21/10/1983 se comporta de forma crescente. Por outro lado, em 1982 os valores decrescem, justificando, portanto, o contraste entre as imagens no realce das áreas úmidas na planície aluvial.

Segundo Santos et al. (2008) o profundo encaixamento do canal e a ocorrência de altos diques marginais fazem com que a planície de inundação do rio Ivaí se comporte como um terraço, sujeito a inundações somente em cheias extremas. Além disso, em virtude da atividade antrópica na modificação das feições geomorfológicas na região de planície deste rio, não se verificam o processo de rompimento de diques marginais (crevasse splay) nesta área, como encontrados, por exemplo, na planície aluvial do alto rio Paraná.

As cheias do rio Ivaí são restritas, devido ao encaixamento do canal fluvial e que o transbordamento do canal principal se dá pelos tributários de pequena ordem, devido a grande altura dos diques marginais (SANTOS et al., 2010). As cheias ocorrentes nos anos de 1982 e 1983 estão relacionadas com o fenômeno El Niño como demonstram os trabalhos de Andrade e Nery (2003) e Baldo (2006). No entanto, Baldo (op. cit.) não verificou relação deste fenômeno para o ano de 1990.

As imagens orbitais de 15/06/1983 e 17/01/1990 respectivamente (Figura 3) ilustram episódios de cheias extremas no curso inferior do rio Ivaí, realçando a 
inundação da água lateralmente ao canal fluvial e no sentido a montante da foz deste rio. Apesar disso, não foram registrados valores diários de cota fluviométrica e vazão na estação fluviométrica no ano de 1983. Releva-se, portanto a atenção para a imagem de 1990, por se apresentar visualmente em ótima qualidade (mínima condição de nuvens possível) e por existirem registros diários das variáveis hidrológicas. Assim, com o valor de 12,01 m de cota fluviométrica e vazão de 3749,1 $\mathrm{m}^{3} / \mathrm{s}$, verificou-se que a água nesta imagem, inunda áreas da planície aluvial com maior realce de feições geomorfológicas quando comparado com a imagem da cheia de 1983, Figura 5.

Observa-se nesta figura, que a água reestabeleceu conexão com paleocanais e lagoas em patamares mais elevados da planície e com proximidade a unidade terraço aluvial cartografada por Santos et al., (2008). Segundo Biazin (2005) os maiores picos de vazões máximas do segmento inferior do rio Ivaí, para a Estação do Novo Porto Taquara, aconteceram nos anos de 1976, 1983, 1987, 1990 e 1993, bem como com maior ocorrência nos meses de janeiro e maio. Além disso, com uma vazão de $3749,1 \mathrm{~m}^{3} / \mathrm{s}$, esta cheia aproximou-se da média das cheias na estação (4019 m³/s), demonstrando uma inundação histórica, sendo também verificada na planície de inundação do alto rio Paraná e rio Ivinhema como já abordado nos trabalhos de Comunello (2001); Meurer (2003) e Comunello et al., (2003). Sendo assim, esta cheia também foi influenciada pelo rio Paraná, que se encontrava nesta data com o valor de $7,88 \mathrm{~cm}$ de cota fluviométrica diária, por meio da estação fluviométrica de Porto São José (código 64575003).

Os valores diários de cota fluviométrica $(\mathrm{m})$ e precipitação pluviométrica $(\mathrm{mm})$ do mês de janeiro de 1990 se encontram no gráfico da Figura 6. Verifica-se na figura, que os valores de cota fluviométrica acompanham os picos de subida e descida de precipitação. Isso demonstra, por exemplo, a contribuição da precipitação na elevação do nível das águas no canal fluvial, sendo que os maiores valores pluviométricos ocorreram nos dias que antecedem a data do imageamento pelo satélite. 


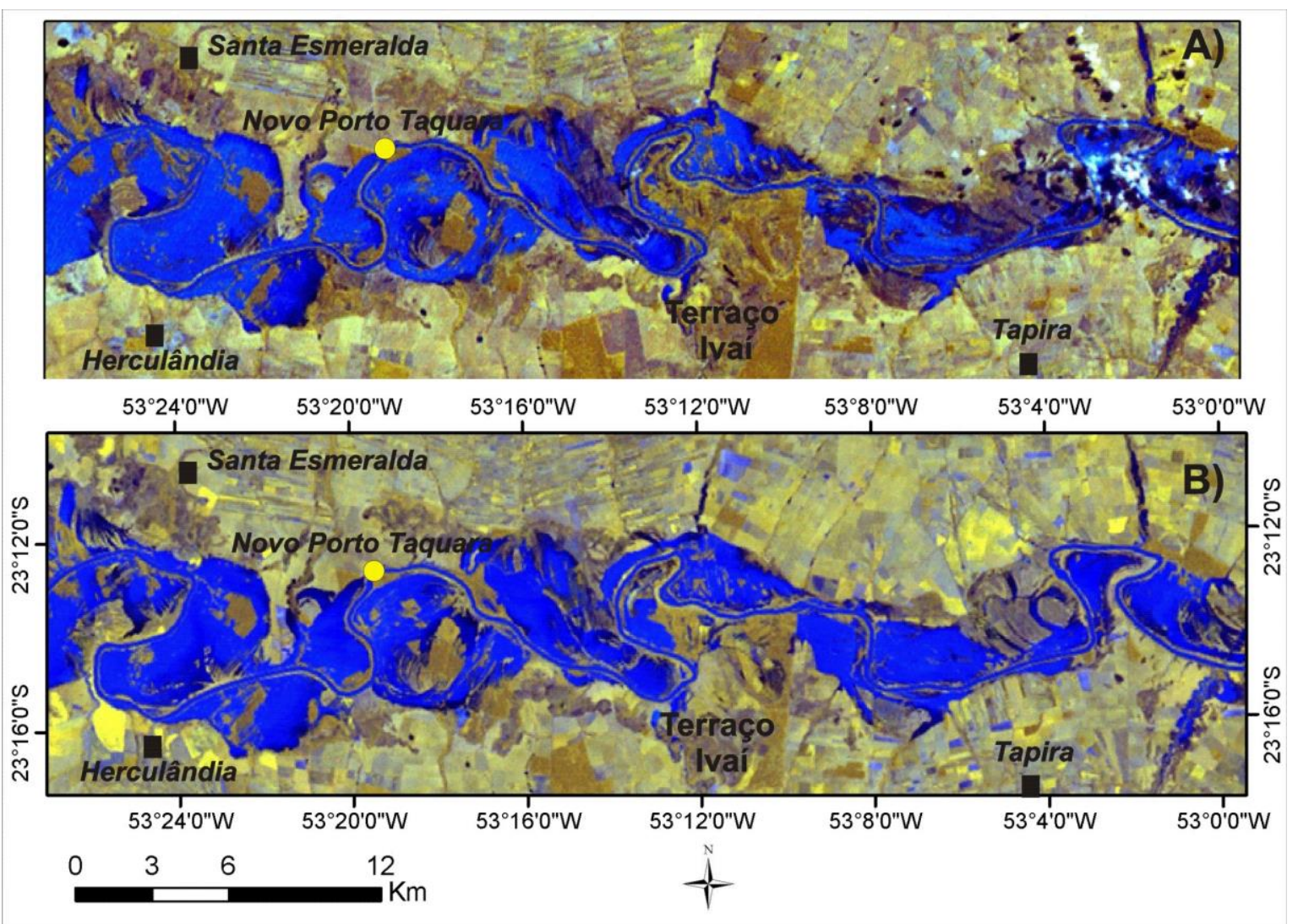

Figura 5 - Eventos de cheias no curso inferior do rio Ivaí, com inundação em patamares mais elevados de sua planície aluvial nas datas de 15/06/1983 (A) e 17/01/1990 (B).

Fonte: Imagens orbitais Landsat 4 e 5 sensor MSS na composição colorida falsa cor R4G3B1

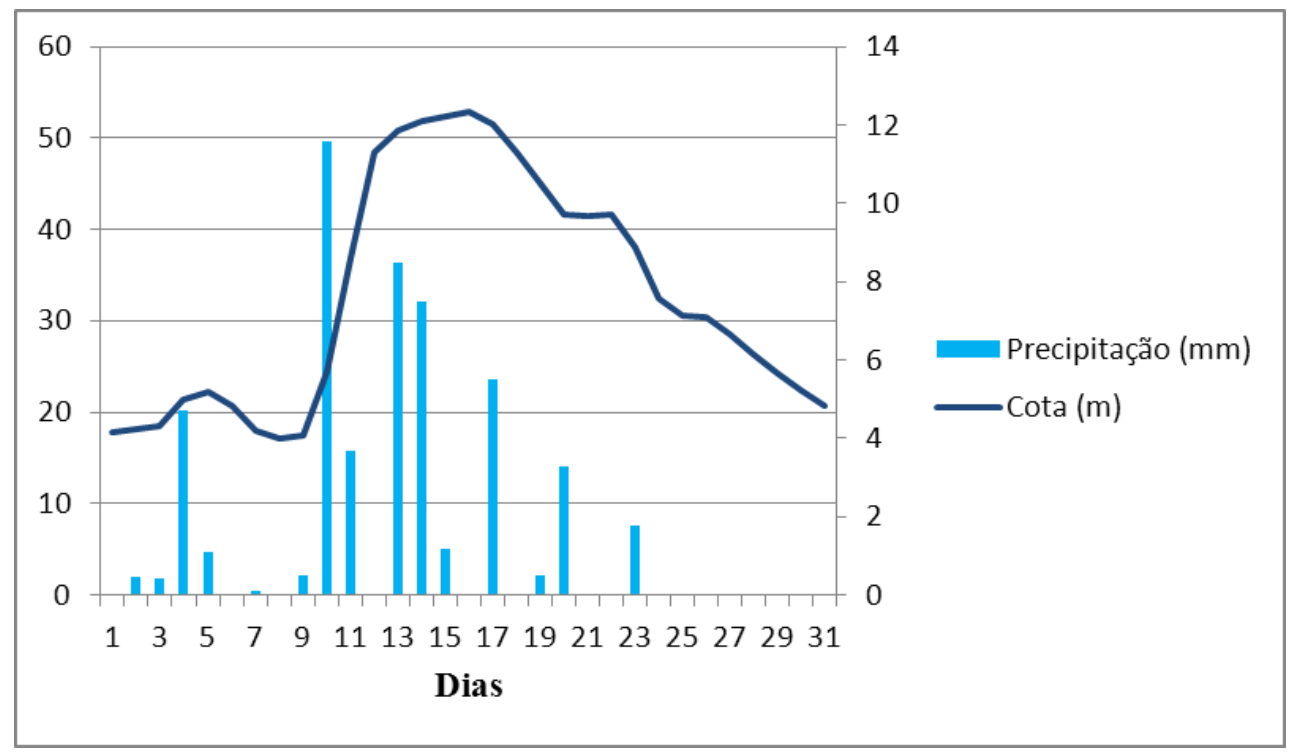

Figura 6 - Valores diários de cota fluviométrica $(\mathrm{m})$ e precipitação pluviométrica (mm) do mês de janeiro de 1990, pela estação fluviométrica e pluviométrica de Novo Porto Taquara (códigos 64693000 e 2353044) 


\section{Considerações finais}

A utilização de imagens orbitais para análise temporal de eventos de cheia do rio Ivaí, possibilitaram de forma indireta a análise das transformações ocorrentes em sua planície aluvial. A relação com variáveis hidrológicas proporcionou uma caracterização preliminar da dinâmica de inundação deste importante sistema fluvial paranaense em seu curso inferior, embora tenha se utilizado de um conjunto restrito de variáveis. Contudo, a utilização de imagens orbitais e variáveis hidrológicas poderão proporcionar a cartografia da área estudada e delimitação de áreas inundáveis.

Foi verificada a importância da cheia ocorrente em 17/01/1990, que promoveu a inundação da área em patamares elevados da planície aluvial do rio Ivaí, realçando com maior detalhamento as feições geomorfológicas. Essa cheia foi influenciada a partir do evento conjunto ocorrente nos rios Ivaí, Paraná, bem como no Ivinhema, conforme constatado por meio do referencial teórico. Observou-se a importância da variável precipitação e sua influência na elevação das águas do canal fluvial. Além disso, para estudos posteriores, deve ser considerado a importância do lençol freático na elevação das águas do canal fluvial e sua contribuição nas cheias, embora não tenha sido utilizado na discussão do presente trabalho.

\section{Referências}

ANDRADE, A.R.; NERY, J.T. Análise da precipitação pluviométrica diária, mensal e interanual da bacia hidrográfica do Rio Ivaí, Brasil. Investigaciones Geográficas, Boletín del Instituto de Geografía. UNAM, México, n. 52, p. 7-30, 2003.

AQUINO, S.; LATRUBESSE, E.M.; SOUZA FILHO, E.E. Relações entre o regime hidrológico e os ecossistemas aquáticos da planície aluvial do rio Araguaia. Acta Scientiarum Biological Sciences, v 30, n. 4. p. 361-369, 2008.

BALDO, M.C. Variabilidade pluviométrica e a dinâmica atmosférica na bacia hidrográfica do rio Ivaí. 2006. 153p. Tese (Doutorado em Geografia), Universidade Estadual Paulista - UNESP. Presidente Prudente, 2006. 
BARROS, C.S. Dinâmica sedimentar e hidrológica na confluência do rio Ivaí com o rio Paraná, município de Icaraíma- PR. 2006. 69p. (Mestrado em Geografia), Universidade Estadual de Maringá-UEM, Maringá, 2006.

BIAZIN, P.C. Característica Sedimentar e Hidrológica do Rio Ivaí em sua Foz com o Rio Paraná, Icaraíma - PR. 2005. 70p. Dissertação (Mestrado em Análise Regional e Ambiental, Departamento de Geografia), Universidade Estadual de Maringá - UEM. Maringá, 2005.

CLARKE, R.T.; TUCCI, C.E.M.; COLLISCHONN, W. Variabilidade temporal no regime hidrológico da bacia do rio Paraguai. Revista brasileira recursos hídricos. v. 8. n.1. p. 201-211, 2003.

COMUNELLO, E. Dinâmica de inundação de áreas sazonalmente alagáveis na planície aluvial do alto rio Paraná. 2001. 47p. Dissertação (Mestrado em Ecologia de Ambientes Aquáticos Continentais) - Departamento de Biologia, Universidade Estadual de Maringá - UEM, Maringá, 2001.

COMUNELLO, E.; SOUZA FILHO, E.E.; ROCHA, P.C.; NANNI, M.R. Dinâmica de inundação de áreas sazonalmente alagáveis na planície aluvial do alto rio Paraná: estudo preliminar. In: Simpósio Brasileiro de Sensoriamento Remoto, XI, Belo Horizonte. Anais, São José dos Campos: INPE, 2003.

COUTO, E.V.; HAYAKAWA, E.H.; SOUZA FILHO, E.E. Diagnóstico dos efeitos causados pelas cheias excepcionais de 1982/1983 sobre a planície inundacional do alto rio Paraná (PR-MS). GEOMAE - Geografia, Meio Ambiente e Ensino. v.1, n.1, p.83-99, 2010.

DESTEFANI, E.V. Regime hidrológico do rio Ivaí - PR. 2005. 93p. Dissertação (Mestrado em Geografia), Universidade Estadual de Maringá - UEM. Maringá, 2005.

ESRI. ArcGIS Desktop 9.2. Guides Book. 2006.

FERNANDEZ, O.V.Q. Determinação do nível e da descarga de margem plena em cursos fluviais. Boletim da Geografia. Universidade Estadual de Maringá, Maringá, 21. Pg. 97- 109, 2003.

JENSEN, J. Sensoriamento Remoto do Ambiente: Uma Perspectiva em

Recursos Terrestres: tradução: EPIPHANIO J. C. N. (coordenador)... (et. al.). 2. ed. São José dos Campos: Parêntese, 2009.

KUERTEN, S. Variação longitudinal das características sedimentares e hidrológicas do rio Ivaí - PR em seu curso inferior. 2006. 97p. Dissertação (Mestrado em Geografia). Universidade Estadual de Maringá - UEM. Maringá, 2006.

KUERTEN S.; SANTOS, M.L.; SILVA, A. Variação das características hidrosedimentares e geomorfologia do leito do Rio Ivaí - PR, em seu curso inferior. Revista Geociências, v 28, n. 2, p. 143 - 151, 2009. 
MEURER, M. Análise dos regimes de cheias dos rios Paraná e Ivinhema, na região de Porto Rico, PR. Geografia, Rio Claro, v. 28, n.2, p.185-195, 2003.

MINEROPAR. Atlas geológico do Estado do Paraná. Curitiba, CD-ROM, 2000.

MORAIS, E.S. Evolução da planície de inundação e confluência do rio Ivaí e rio Paraná na região do pontal do tigre, Icaraíma - PR: Uma abordagem geomorfológica. 2010. 65p. Dissertação (Mestrado em Geografia). Universidade Estadual de Maringá- UEM. Maringá, 2010.

PARANÁ. Secretaria de Estado da Agricultura e do Abastecimento. Instituto de Terras, Cartografia e Floresta. Atlas do estado do Paraná. Curitiba: UFPR, 1987.

ROCHA, P.C. Dinâmica dos Canais no Sistema Rio-Planície Fluvial do Alto Rio Paraná, nas Proximidades de Porto Rico-PR. 2002. 171p. Tese (Doutorado em Ecologia de Ambientes Aquáticos Continentais) - Universidade Estadual de MaringáUEM. Maringá, 2002.

RSI. Environment for Visualizing Images - ENVI. ver. 4.5. Boulder, CO, USA: ITT Industries. 2008.

SANTOS, M.L.; STEVAUX, J.C.; GASPARETTO, N.V.L.; SOUZA FILHO, E. E. Geologia e geomorfologia da planície aluvial do rio Ivaí em seu curso inferior. Revista brasileira de Geomorfologia, v.9, n.1, p. 23 - 34, 2008.

SANTOS, M.L.; KUERTEN, S.; GASPARETTO, N.V.L. Variação longitudinal da hidrodinâmica, morfologia do canal e carga sedimentar do baixo curso do rio Ivaí Paraná, Brasil. In: V Congresso Nacional de Geomorfologia, Porto. Volume de actas/ proceedings do V Congresso Nacional de Geomorfologia. Porto: Associação Portuguesa de Geomorfologia, v. 1, p. 151-156, 2010.

SMITH, L.C. Satellite remote sensing of river inundation area, stage, and discharge: a review.Hydrological Process, 11:1427-1439, 1997.

SOARES, P.C.; LANDIM, P.M.B.; FÚLFARO, VJ.; SOBREIRO NETO, A.F. Ensaio de caracterização estratigráfica do Cretáceo no estado de São Paulo: Grupo Bauru. Revista Brasileira de Geociências, 1980, 10(3): 177-185.

SOUZA FILHO, E.E. Evaluation of the Upper Paraná River discharge controlled by reservoirs. Revista Brasileira de Biologia, Brazilian Journal of Biology, vol. 69, no. (2 suppl), p. 707-716. 2009.

SOUZA JUNIOR, M.D. Efeitos tectônicos na formação da paisagem da bacia hidrográfica do rio Ivaí, curso inferior. Dissertação do Manoel. 2012, 125p. Dissertação (Mestrado em Geografia). Universidade Estadual de Maringá - UEM, Maringá, 2012. 
VALERIANO, M.M.; ROSSETTI, D.F. Topodata: Brazilian full coverage refinement of SRTM data. Applied Geography (Sevenoaks) v. 32, p. 300-309, 2011.

VILLELA, S.M.; MATTOS, A. Hidrologia aplicada. São Paulo: McGraw-Hill do Brasil, 245p, 1975. 